\title{
Effect of Somatostatin on Blood Levels of Motilin and the Interdigestive Myoelectric Complex in Dogs
}

\author{
P. POITRAS, J. H. STEINBACH, G. VAN DEVENTER \\ C. F. CODE AND J. H. WALSH \\ VA Wadsworth Hosp. Center, Bldg. 115, \\ Rm. 217, Los Angeles, California, USA
}

\begin{abstract}
Motilin has been called an interdigestive hormone, suspected to induce the interdigestive myoelectric complex (IDMC) in dog (Itoh et al., 1978). Somatostatin (GH-RIH) has been shown to inhibit motilin release in man (Mitznegg et al., 1977). The following study was designed to look at the effect of GH-RIH on blood levels of motilin and on the IDMC in dog.
\end{abstract}

\section{Methods}

\section{A) Radioimmunoassay for motilin}

Synthetic porcine motilin (gift from Dr. H. C. Beyerman, Guelph, Netherlands) was iodinated by Hunter and Greenwood's technique (1963). Motilin labeled with ${ }^{125}$ I was purified on G-10 Sephadex and CM Sephadex G-25 columns. Motilin antibody (obtained from Dr. Yanaihara, Shizuoka, Japan) was used in a final dilution of $1 / 200,000$. This antibody did not cross react with $10 \mathrm{pmol}$ of gastrin 17 , secretin, pancreatic polypeptide, bombesin, VIP, GIP or somatostatin. The antibody was specific for the central portion of motilin. At a final dilution of $1: 10$, the assay was sensitive to $50 \mathrm{pg} / \mathrm{m} l$ in plasma and the $\mathrm{ID}_{50}$ was $300 \mathrm{pg} / \mathrm{ml}$ of synthetic motilin added to plasma. The intra-assay variation was between 4.5 and $6.6 \%$ and the inter-assay variation was $8.6 \%$ when tested with plasma motilin concentrations between 100 and $1000 \mathrm{pg} / \mathrm{m} l$.

Supported in part by NIH grants AM 17328, AM 18618 and by the Medical Research Service of the Veteran Administration. P. Poitras was supported by a fellowship grant from Medical Research Council of Canada.

\section{B) Dog experments}

Under general anesthesia, monopolar silver-silver chloride electrodes were implanted to the serosal surface of the antrum and small intestine of mongrel female dogs (Carlson et al., 1975). Recording sessions on conscious animals were begun 2 weeks postoperatively. The dogs were fasted for $15 \mathrm{hr}$ before each experiment. Recordings were made with an 8 channel Brush Mark 200 recorder with the cannula used as an indifferent electrode. The four phases of the interdigestive complex were identified by visual inspection of the electromyograph (Code and Marlett, 1975).

Part 1: Normal cycles of motilin and interdigestive activity. Three dogs were observed in a basal state for 3 consecutive cycles of interdigestive myoelectric complexes. Through an indwelling intravenous catheter, $3 \mathrm{ml}$ samples of blood were collected in EDTA tubes at $10 \mathrm{~min}$ intervals during the whole experiment.

Part 2: Effects of exogenous GH-RIH (somatostatin) on normal cycles. Each experiment was performed once on each of 4 dogs. Thirty min after the end of a recorded activity front (phase III) in the duodenum, GH-RIH (Boeringher Mannheim Biochemicals) was infused at $2.5 \mu \mathrm{g} / \mathrm{kg} / \mathrm{h}$ or $0.625 \mu \mathrm{g} / \mathrm{kg} / \mathrm{h}$ for $3 \mathrm{hr}$ by a Harvard pump. Each dose was administered on a separate day. In an additional experiment, 2 animals received $5 \mu \mathrm{g} / \mathrm{kg} / \mathrm{h}$.

Part 3: Effect of exogenous GH-RIH on activity induced by exogenous motilin. Each experiment was performed once on 3 dogs. Motilin was administered twice to each dog, once during saline infusion and once during GH-RIH infusion. Synthetic motilin $(0.5 \mu \mathrm{g} / \mathrm{kg} / \mathrm{h}$ for $30 \mathrm{~min}$; gift from Dr. Yajima) was started $30 \mathrm{~min}$ after the end of a spontaneous activity front in the duodenum or $60 \mathrm{~min}$ after the start of GH-RIH. A $2 \mathrm{hr}$ infusion of GH-RIH was administered at $2.5 \mu \mathrm{g} / \mathrm{kg} / \mathrm{h}$ in 2 dogs and $0.625 \mu \mathrm{g} / \mathrm{kg} / \mathrm{h}$ in one dog. The activity induced by infusion of exogenous motilin on a background of GH-RIH was compared to the activity induced by the same dose 



Fig. 1. Spontaneous increase in motilin blood levels concomitant with induction of activity fronts in the duodenum. Blood levels of motilin are shown in the upper part of the graph and are expressed in $\mathrm{pg} / \mathrm{ml}$. The lower two-thirds of the graph represents intestinal electrical activity. The 4 phases are represented graphically as follows: phase I: -; phase II: *; phase III: \#; phase IV: @. Letters on the left margin indicate electrode position. S-stomach, D-duodenum, J-jejunum, I-ileum.

of exogenous motilin on a background of saline in the same dog on the same day.

\section{Results}

Part 1: Normal cycles of motilin and interdigestive activity. In each dog, 3 activity fronts (phase III) started regularly each 90 to $120 \mathrm{~min}$ in the duodenum and propagated to the caecum. The initiation of each of these fronts in the upper intestine was concomitant with a cyclical increase in blood levels of motilin. One representative experiment is shown in Figure 1.

Part 2: Effect of exogenous GH-RIH on normal cycle. A GH-RIH infusion was started $30 \mathrm{~min}$ after the end of an activity front in the duodenum. In all dogs the expected cyclical duodenal activity front was abolished during the $3 \mathrm{hr}$ infusion of GH-RIH $2.5 \mu \mathrm{g} / \mathrm{kg}^{-1} / \mathrm{h}^{-1}$. In 2 dogs the activity of the whole small intestine remained flxed in phase 1 or 2 during this infusion (Figure 2). In 2 dogs, a propagating activity front started in the jejunum despite the infusion. When GH-RIH was increased to $5 \mu \mathrm{g} / \mathrm{kg}^{-1} / \mathrm{h}^{-1}$, a jejunal front failed to occur in one of these dogs but was still observed in the other. In all dogs, the expected cyclic increase of motilin did not occur during infusion of GH-RIH and the blood concentrations of motilin were less than the lowest concentrations measured in a normal cycle. After the cessation of GH-RIH, motilin concentration increased immediately. 

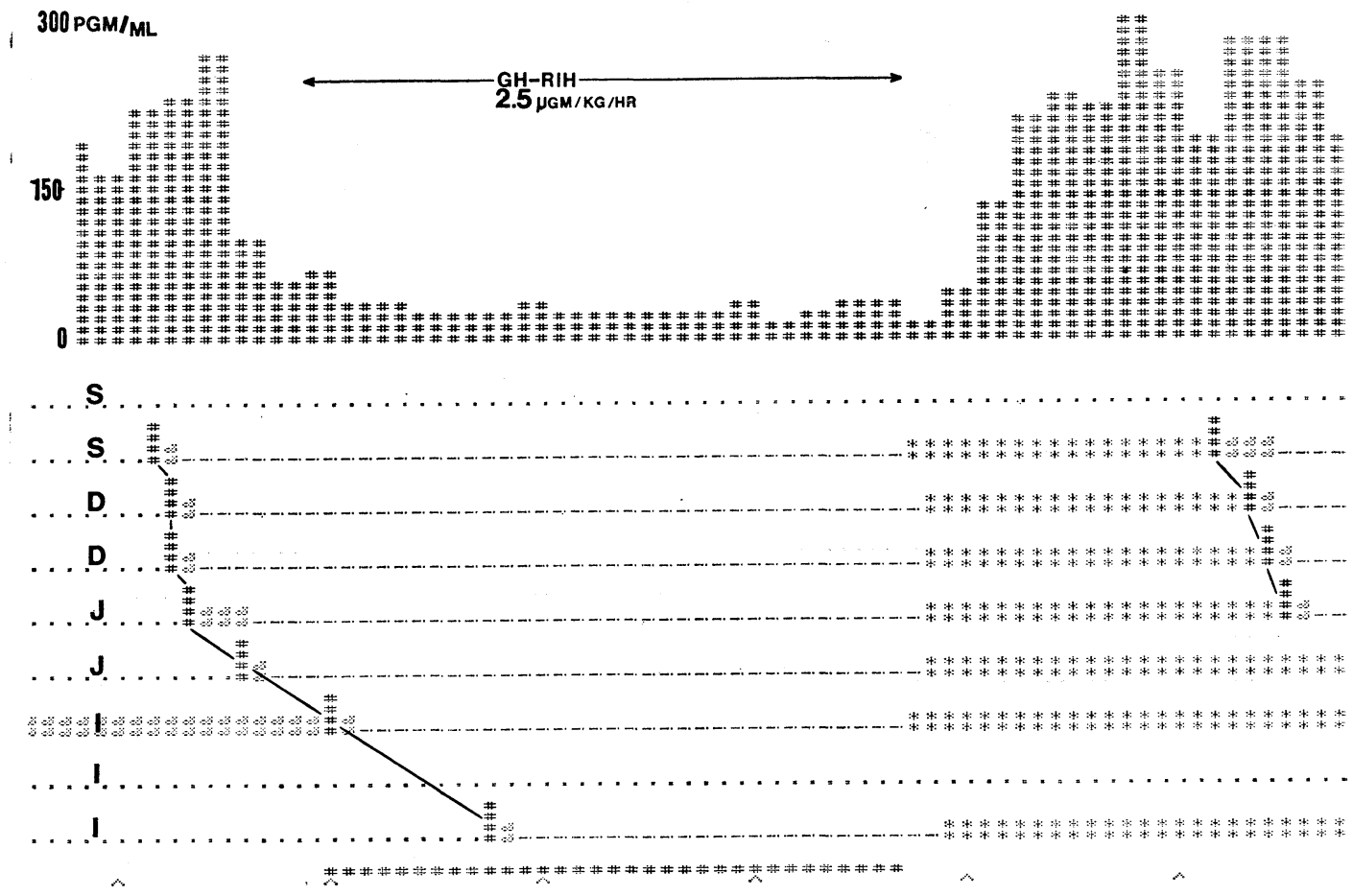

Fig. 2. During GH-RIH infusion motilin release was blocked and no activity front occurred in the duodenum or lower intestine.

When a smaller dose of GH-RIH was infused $\left(0.625 \mu \mathrm{g} / \mathrm{kg}^{-1} / \mathrm{h}^{-1}\right)$, in $3 \mathrm{dogs}$, the expected cyclical increase of motilin did not occur, nor did the expected cyclical phase III in duodenum, but in each dog, activity fronts started in jejunum or ileum and propagated to the ileocecal valve.

All duodenal fronts initiated before the GH-RIH infusion was begun were propagated normally to the caecum as were the fronts initiated in the distal intestine during the infusion of GH-RIH.

Part 3: Effect of exogenous GH-RIH on the activity induced by exogenous motilin. In all dogs, the administration of motilin $\left(0.5 \mu \mathrm{g} / \mathrm{kg}^{-1} / \mathrm{h}^{-1}\right.$ for $\left.30 \mathrm{~min}\right)$ during an infusion of saline induced an activity front which started in the duodenum and propagated normally over the entire small bowell. However when GH-RIH was given, the same dose of motilin failed to induce a front despite an increase in motilin blood concentrations. In each dog the myoelectrical activity increased with motilin infusion but never reached the level of a phase 3 (50 or more consecutive pacesetter with multiple action potentials on each pacesetter).

\section{Discussion}

Inhibitory effects of GH-RIH on the IDMC of the dog have been reported previously by Lee and Chey (1976) and Ormsbee et al. (1978). Our study indicates that such an action may be mediated by an inhibitory effect on motilin release or by a direct action on the intestinal smooth muscle. Dual and complementary actions of 


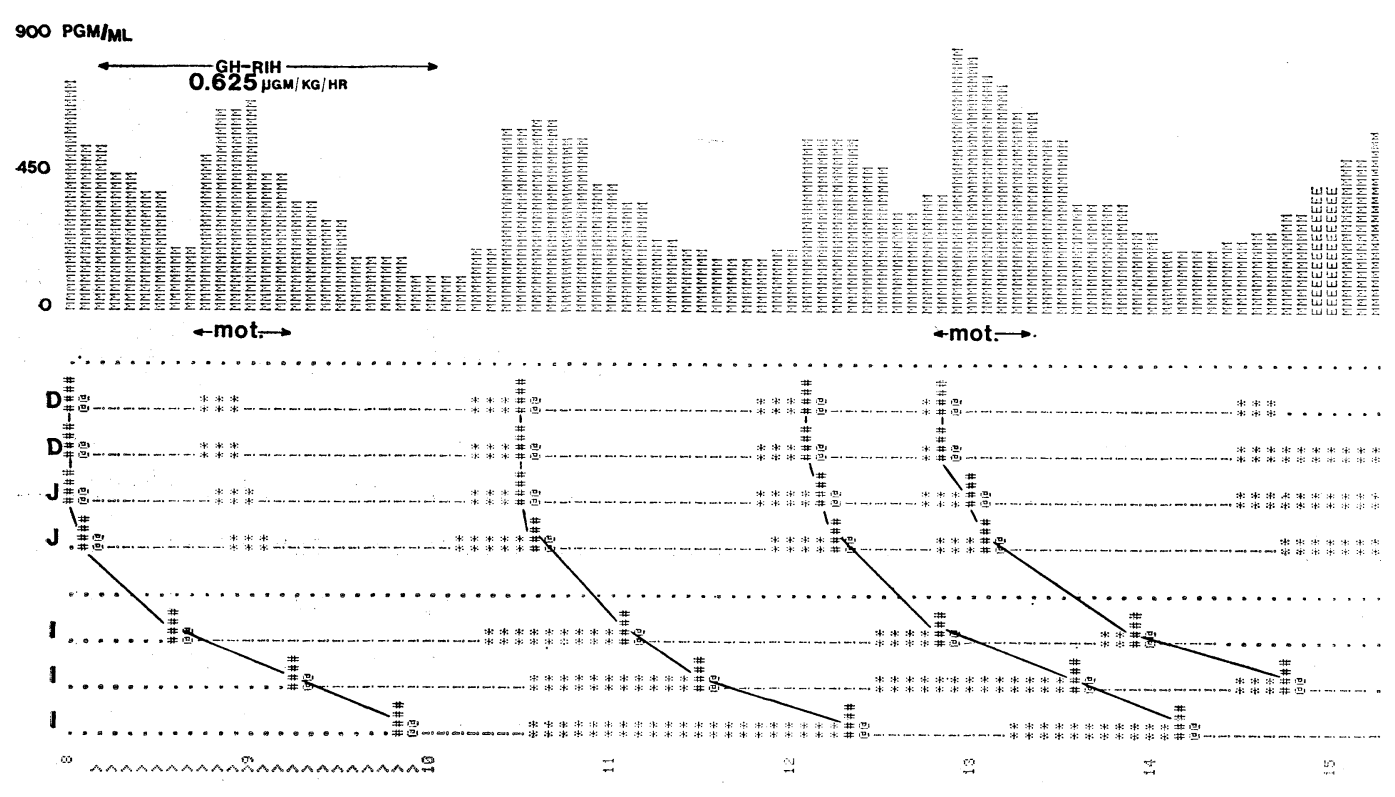

Fig. 3. Administration of motilin (mot.) during somatostatin infusion failed to induce an activity front.

GH-RIH have been described before when GH-RIH inhibited the release of gastrin and secretin and their respective stimulatory actions on gastric and pancreatic secretions (Konturek et al., 1976a, b, Raptis et al., 1975, 1978).

Our study supports the theory that motilin is the physiological inducer of activity fronts of the IDMC in the canine duodenum. Our results also suggest that the propagation of an activity front along the small intestine and the induction of activity fronts in jejunum or lower in the ileum are motilin independent.

\section{References}

Carlson, G. M., B. S. Bedi and C. F. Code (1975). Am. J. Physiol. 222, 289.

Code, C. F. and J. A. Marlett (1975). J. Physiol. 246, 289.
Hunter, W. M. and F. C. Greenwood (1963). Nature 194, 495.

Itoh, Z., S. Takeuchi, I. Aizawa, R. Takayanagi, K. Mori, T. Taminato, Y. Seino, H. Imura and N. Yanaihara. In Gastrointestinal Hormones and Pathology of the Digestion System (edited by M. I. Grossman, V. Speranza, N. Basso and E. Lazoche). Plenum Press, New York and London, p. 241 (1978).

Konturek, S. J., J. Tasler, M. Cieszkowski, D. H. Coy and A. V. Schally (1976a). Gastroenterology 70, 737.

Konturek, S. J., J. Tasler, W. Obtulowicz, D. H. Coy and A. V. Schally (1976b). J. Clin. Invest. $58,1$.

Lee, K. Y. and W. Y. Chey (1976). The Physiologist $19,266$.

Mitznegg, P., S. R. Bloom, W. Domschke, S. Domschke, E. Wünsch and L. Demling (1977). Gastroenterology 72, 413.

Ormsbee, H. S., S. L. Koehler, Jr. and G. L. Telford (1978). Am. J. Dig. Dis. 23, 781.

Raptis, S., H. C. Dollinger, L. von Berger, W. Schlegel, K. E. Schroder and E. F. Pfeiffer (1975). Digestion 13, 15.

Raptis, S., W. Schlegel, E. Lehmann, H. C. Dollinger and C. H. Zoupas (1978). Metabolism 27, 1321. 